\title{
KINETICS AND MECHANISM OF THE SILVER (I) OXIDE TO SILVER (II) OXIDE LAYER ELECTROOXIDATION REACTION
}

\author{
R. C. Salvarezza, J. Gómez Becerra and A. J. Arvia
}

Instituto de Investigaciones Fisicoquímicas Teóricas y Aplicadas (INIFTA), Facultad de Ciencias Exactas, Universidad Nacional de La Plata, Sucursal 4, Casilla de Correo 16, (1900) La Plata, Argentina

(Received 7 March 1988, in revised form 24 May 1988)

\begin{abstract}
The electroformation of $\mathrm{Ag}(\mathrm{II})$ oxide layer during the anodization of silver in $0.1 \mathrm{M} \mathrm{NaOH}$ is investigated under potentiostatic and potentiodynamic conditions. Results are discussed in terms of nucleation and growth models and statistical analysis of induction times related to the nucleation kinetics of Ag(II) oxide crystals. The best fitting of results comes out from the application of a progressive nucleation and 3-D growth model under mass transfer control where diffusion of species from the electrode to growing sites is essential for further expansion.
\end{abstract}

\section{INTRODUCTION}

The anodization of silver electrodes in alkaline solutions has been extensively investigated. Reviews on the subject are given in references[1-5]. The anodic reaction involves two oxidation levels corresponding to $\mathrm{Ag}_{2} \mathrm{O}$ and $\mathrm{AgO}$ formation. The corresponding reactions were principally investigated at $298 \mathrm{~K}$, although data down to $258 \mathrm{~K}$ [3] and up to $478 \mathrm{~K}$ has been reported $[6,7]$.

The first oxidation level comprises as a first step the formation of a AgOH monolayer [8-11] followed by thickening to produce a homogeneous $\mathbf{A g}(\mathbf{I})$ oxide primary layer. A second $\mathrm{Ag}(\mathrm{I})$ oxide layer is formed through nucleation and 3-D growth under diffusion control of isolated $\mathrm{Ag}(\mathrm{I})$ oxide centers[12-15].

The second oxidation level of silver anodization corresponds to the formation of a Ag(II) oxide layer on top of the complex Ag(I) oxide layer[5]. Earlier kinetic studies of $\mathrm{Ag}$ (II) oxide formation[11, 16-19] were interpreted through different mechanisms, that is either a conventional heterogeneous electrochemical reaction mechanism, such as the autocatalytic mechanism [17] and the transfer of $\mathrm{O}^{2-}$ ions at the $\mathrm{Ag}_{2} \mathrm{O}-\mathrm{AgO}$ interface[16], or nucleation and growth rate controlling processes $[5,10,11,18,19]$. These models, however could not explain the marked decrease in the $\mathbf{A g}(\mathrm{II})$ oxide charge with potential result-. ing from the crystal formation under a constant applied potential set in the $0.51-0.56 \mathrm{~V}$ range ( $v s$ sce). Nevertheless, despite these discrepancies it should be noticed that the kinetic interpretation based upon a progressive nucleation of AgO centers coupled with 3-D growth appears as the most satisfactory one[18]. It implies a mechanism of lattice formation based on the concentration and potential dependence of crystal growth.

The present paper refers to the electroformation of the $\mathrm{Ag}(\mathrm{II})$ oxide layer under potentiodynamic and potentiostatic conditions. Data are discussed in terms of both a nucleation and growth model which accounts for the entire current transient behaviour complemented with a statistical analysis of the induction times related to the nucleation kinetics of the Ag(II) oxide crystals.

\section{EXPERIMENTAL}

Working electrodes were made of polycrystalline (pc) Ag $(99.99 \%$ purity) rods axially embedded in Araldite cylindrical holders to obtain circular silver exposed areas of $0.05 \mathrm{~cm}^{2}$ apparent area surrounded by an insulating ring of $0.6 \mathrm{~cm}$ outer dia. The electrodes were mechanically polished starting with fine grained emery paper and followed with alumina paste of $1 \mu \mathrm{m}$ dia. to obtain mirror polished silver electrode surfaces. Before the electrochemical measurements the electrodes were degreased with alcohol and rinsed with triply distilled water. Precautions were taken to avoid crevices between Ag rods and Araldite holders which could lead to artifacts in the electrochemical measurements. The counter electrode was a large $\mathrm{Pt}$ sheet located in a separate cell compartment. The potential of the working electrode was measured against a saturated calomel electrode (sce) connected to the working electrode cell compartment through a Luggin-Haber capillary tip. Potentials in the text are referred to the sce. The electrolyte solution was $0.1 \mathrm{M} \mathrm{NaOH}$ prepared from triply distilled water and AR chemicals. Solutions were bubbled with purified nitrogen for $3 \mathrm{~h}$ prior to the electrochemical runs. The working electrode was subjected only to a single triangular potential scan between the cathodic $\left(E_{\mathrm{s}, \mathrm{c}}\right)$ and the anodic $\left(E_{\mathrm{s}, \mathrm{a}}\right)$ switching potentials. Repetitive potential scans were specifically avoided as the electroreduction of the silver oxide layer results in reformed[5] Ag surfaces made of a large number of overlapping nuclei with complex diffusional paths. For this reason a new fresh polished $\mathrm{Ag}$ electrode was required for each measurement. Current transients at constant potential were obtained in the conventional way by using the perturbing potential programs described in the text. In all these cases the Ag electrodes 
were held at $E_{\mathrm{s.c}}=-1.20 \mathrm{~V}$, for $60 \mathrm{~s}$, to start every electrochemical run with a reproducible electroreduced silver electrode surface. All measurements were made at $T=25^{\circ} \mathrm{C}$. Experiments were also made by using a working electrode consisting of a $\mathrm{Ag}(\mathrm{I})$ oxide layer chemically precipitated on the base of a spectroscopy grade graphite rod $\left(0.28 \mathrm{~cm}^{2}\right)$. The purpose of this electrode was to investigate the $\mathrm{Ag}(\mathbf{I})$ oxide $\rightarrow A g(I I)$ oxide reaction without the possible interference of base silver phase electrochemical reactions. The precipitation of the Ag(I) oxide was made by alternately dipping in $0.1 \mathrm{M} \mathrm{AgNO}_{3}$ and $0.1 \mathrm{M} \mathrm{NaOH}$ solutions as indicated elsewhere[20].

\section{RESULTS}

\section{Voltammetric data}

The $j-E$ profile of a polycrystalline silver electrode immersed in $0.1 \mathrm{M} \mathrm{NaOH}$ run at $v=0.5 \times 10^{-3} \mathrm{~V} \mathrm{~s}^{1}$ between $E_{\mathrm{s}, \mathrm{c}}=-0.2 \mathrm{~V}$ and $E_{\mathrm{s}, \mathrm{a}}=0.65 \mathrm{~V}$ shows up in the positive potential going scan peaks $A_{1}^{\prime}$ and $A_{1}^{\prime \prime}$ at $0.23 \mathrm{~V}$ and $0.28 \mathrm{~V}$, respectively, followed by a current decay until the potential reaches $0.53 \mathrm{~V}$ (Fig. 1). By further increasing the potential just a few $\mathrm{mV}$ a sudden increase in current defining a very sharp peak $\left(\mathrm{A}_{2}\right)$ located at $0.55 \mathrm{~V}$ can be observed. The returning scan from $0.6 \mathrm{~V}$ downwards shows a broad peak $\left(\mathrm{C}_{2}\right)$ at $0.37 \mathrm{~V}$ and a sharp peak $\left(C_{1}\right)$ at $0.10 \mathrm{~V}$. Peaks $A_{1}^{\prime}$ and $A_{1}^{\prime \prime}$ are related to the electroformation of the primary Ag(I) oxide layer and to the nucleation and 3-D growth of the secondary $\mathrm{Ag}(\mathrm{I})$ oxide layer, respectively. The electroreduction of the complex $\mathrm{Ag}(\mathrm{I})$ oxide layer occurs in the potential range of peak $C_{1}$ leading to a reformed silver surface composed by a large number of overlapped nuclei[5]. The processes involved in the electroformation of the $\mathrm{Ag}(\mathrm{I})$ oxide layer were already discussed elsewhere[12]. Likewise, peak $\mathrm{A}_{2}$ is attributed to the electroformation of an $\mathbf{A g}(\mathrm{II})$ oxide layer and peak $C_{2}$ is assigned to the electroreduction of the $\mathbf{A g}(\mathrm{II})$ oxide layer to form $\mathbf{A g}(\mathrm{I})$ oxide [5, 12].

The height of peak $\mathrm{A}_{2}\left(j_{\mathrm{p}}\right)$ vs $v^{1 / 2}$ plot (Fig. 2) exhibit two linear portions with a crossing point at $v \cong 1 \mathrm{mV} \mathrm{s}^{-1}$. Similarly two linear relationships are observed by plotting the potential of peak $A_{2}\left(E_{p}\right)$ vs $\log v$ (Fig. 3) with the slopes $0.03 \mathrm{~V} \mathrm{dec}^{-1}$ and $0.09 \mathrm{~V} \mathrm{dec}^{-1}$, respectively. The charge density $\left(q_{\mathrm{A}_{2}}\right)$ obtained from peak $\mathrm{A}_{2}$ decreases sharply as $v$ increases. Otherwise, $q_{C_{2}}$, the charge density derived from peak $C_{2}$, is considerably smaller than $q_{C_{1}}$, the charge density of peak $C_{1}$, the corresponding ratio being $\left(q_{\mathrm{C}_{2}} / q_{\mathrm{C}_{1}}\right) \cong 0.3$. To evaluate the contribution of the electrooxidation of $\mathrm{Ag}$ substrate and that of the $\mathrm{Ag}(\mathrm{I})$ oxide phases to the processes occurring at $A_{2}$, the voltammetric data derived from the $\mathrm{Ag}(\mathrm{I})$ oxide layer chemically deposited onto a graphite disc electrode becomes important. For this purpose the $\mathrm{Ag}(\mathrm{I})$ oxide electrode was polarized at $0.4 \mathrm{~V}$, that is in the $\mathrm{Ag}_{2} \mathrm{O}$ electroformation potential range (Fig. 1), and subsequently potential scanned up to $0.65 \mathrm{~V}$ and backwards to $-0.2 \mathrm{~V}$. The corresponding $j-E$ profile exhibits the same characteristics already depicted in Fig. 1 with nearly the same $q_{C_{2}} / q_{C_{1}}$ ratio. This fact is a clear indication that the process occurring in the

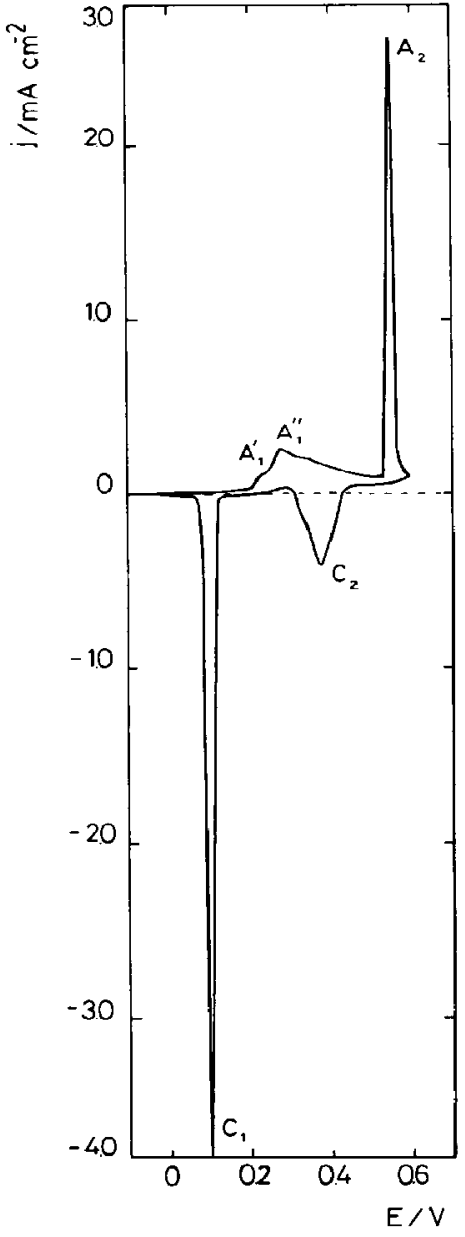

Fig. 1. Voltammogram for a polycrystalline $\mathrm{Ag}$ electrode run in $0.1 \mathrm{M} \mathrm{NaOH}$ at $25^{\circ} \mathrm{C}$ between $E_{\mathrm{s}, \mathrm{c}}=-0.2 \mathrm{~V}$ and $E_{\mathrm{s} . \mathrm{a}}$ $=0.6 \mathrm{~V}$ at $v=0.5 \times 10^{-3} \mathrm{~V} \mathrm{~s}^{-1}$.

potential range of peak $A_{2}$ involves only a partial conversion of the $\mathrm{Ag}(\mathrm{I})$ oxide into $\mathrm{Ag}(\mathrm{II})$ oxide. According to $\mathrm{X}$-ray diffraction data the $\mathbf{A g}(\mathrm{II})$ oxide layer is formed at the $\mathrm{Ag}_{2} \mathrm{O}$ layer side in contact with the electrolyte[21].

\section{Potentiostatic current transients}

Current transients run under a preset constant potential step $\left(E_{\mathrm{s}}\right)$ were made after applying to the mechanically polished working electrode the following pretrcatment. Firstly, the clectrode was immersed in $0.1 \mathrm{M} \mathrm{NaOH}$ and the potential was held at $E_{\mathrm{c}}=$ $-1.20 \mathrm{~V}$ for $t_{\mathrm{c}}=60 \mathrm{~s}$ to obtain a reproducible electroreduced silver surface. Subsequently, the potential was stepped to $E_{\mathrm{a}}=0.45 \mathrm{~V}$ for $t_{\mathrm{a}}=300 \mathrm{~s}$ to attain a steady condition for the electroformation of the $\mathrm{Ag}(\mathbf{I})$ oxide layer. Changes in $t_{\mathrm{a}}$ from 300 to $1200 \mathrm{~s}$ have no influence in the transient displays. Finally, the potential was stepped to $E_{\mathrm{s}}\left(0.5 \leqq E_{\mathrm{s}} \leqq 0.6 \mathrm{~V}\right)$ to record the 


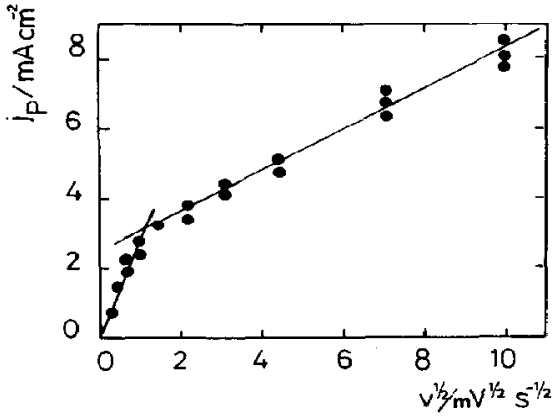

Fig. 2. Peak current $\left(\mathrm{A}_{2}\right)$ vs $v^{1 / 2}$ plot. $0.1 \mathrm{M} \mathrm{NaOH}, 25^{\circ} \mathrm{C}$.

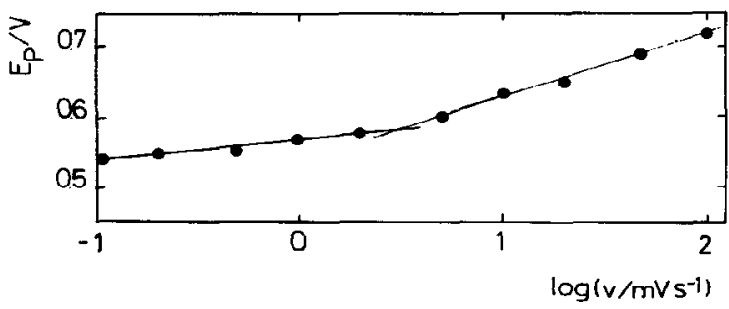

Fig. 3. $E_{\mathrm{p}}\left(\mathrm{A}_{2}\right)$ vs $\log v$ plot. $0.1 \mathrm{M} \mathrm{NaOH}, 25^{\circ} \mathrm{C}$.

current transients related to the partial electrooxidation of the $\mathrm{Ag}(\mathrm{I})$ oxide layer in to $\mathrm{Ag}(\mathrm{II})$ oxide.

The current transients exhibit the following features. Initially the current remains nearly constant (background current) for a certain time. This time can be considered as an induction time $\left(t_{\mathbf{i}}\right)$ related to the oxide conversion process (insert in Fig. 4). Later for $t_{\mathrm{s}}>t_{\mathrm{i}}$, the current increases to attain a maximum $\left(I_{\mathrm{M}}\right)$ at the time $t_{\mathrm{M}}$, and finally for $t>t_{\mathrm{M}}$ the current decreases markedly to approach the initial background current (Fig. 4). As $E_{s}$ shifts in the positive direction both $t_{\mathrm{i}}$ and $t_{\mathrm{M}}$ decrease and $I_{\mathrm{M}}$ increases, but $q$, the charge density involved in the transients decreases sharply as $E_{\mathrm{s}}$ increases (Fig. 5) in contrast to the expectations for a single layer nucleation and growth process[18]. The behaviour of these current transients is similar to those described previously. This charge decrease can be related to the change in the multilayer structure of the anodic layer. As the $E_{\mathrm{s}}$ is positively increased it appears as if a more compact outer AgO layer is produced, ie the passive character of this layer increases, so that only a relatively smaller fraction of $\mathrm{Ag}_{2} \mathrm{O}$ transforms into $\mathrm{AgO}$. This decrease in the yield of $\mathrm{Ag}_{2} \mathrm{O}$ to $\mathrm{AgO}$ reaction has been observed at low temperatures due to slow nucleation [3].

Relcvant information about the growth mode of the Ag(II) oxide nuclei can also be derived from the analysis of the initial rising part of the current transients which in all cases fits $j$ vs $t^{3}$ linear relationships (Fig. 6) which go through the origin of coordinates because the time scale was set for $t=t_{i}=0$. Furthermore, $\operatorname{linear} \log j_{M}$ vs $E_{\mathrm{s}}$ and $\log t_{\mathrm{M}}$ vs $E_{\mathrm{s}}$ plots are also obtained, the slope of the former being close to $0.06 \mathrm{~V} \mathrm{dec}^{-1}$ (Figs 7 and 8 ).

The time dependence of $P_{n \geq 1}$, the probability for the formation of at least one nucleus, can be used to probe new aspects of the nucleation kinetics. For a Poisson distribution and a stationary nucleation rate, $\bar{t}_{\mathrm{i}}$, the mean value of the induction time, is given by[22]:

$$
\overline{t_{\mathrm{i}}}=\frac{1}{\alpha N_{0}},
$$

where $\alpha N_{0}$ is the nucleation rate, $\alpha$ is the nucleation rate constant and $N_{0}$ denotes the number of sites available for nucleation. To test Equation (1) a large number of $t_{\mathrm{i}}$ were measured for each $E_{\mathrm{s}}$ value so that $P_{n \geq 1}$ was obtained as a function of time. The $P_{n \geq 1}$ vs $t$ plots (Fig. 9) indicate that as $E_{\mathrm{s}}$ moves in the positive direction the survival time, i.e. the time for which the sample remains free of AgO nuclei, is drastically reduced.

\section{DISCUSSION}

The present results can be directly discussed within the framework of certain controversial theories about the growth mode of the Ag(II) oxide centers during silver anodization at relatively high anodic potential in basic solutions, in particular the participation of a

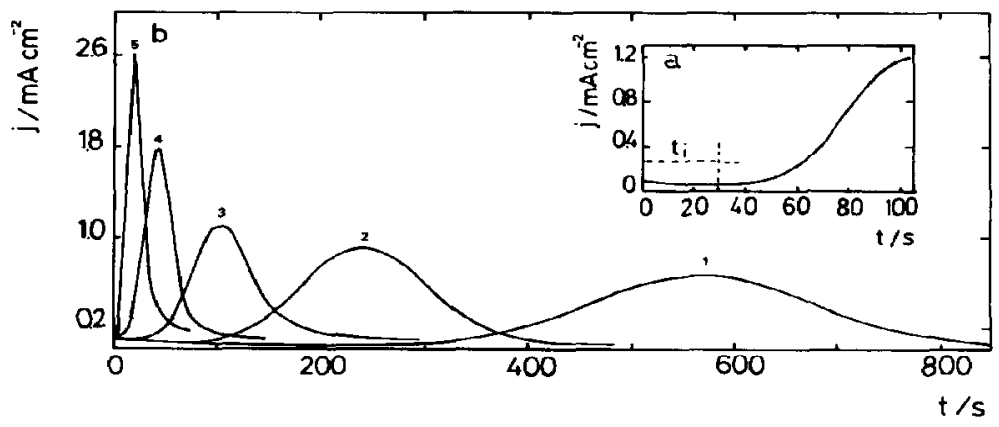

Fig. 4. Potentiustatic current transients of polycrystalline Ag electrode in $0.1 \mathrm{M} \mathrm{NaOH}$ after applying the following successive potential step pretreatment: $E_{\mathrm{c}}=-1.20 \mathrm{~V} ; t_{\mathrm{c}}=60 \mathrm{~s}$ potential holding at $E_{\mathrm{a}}=0.45 \mathrm{~V}$ for $t_{\mathrm{a}}=300 \mathrm{~s}$ and potential stepped to $E_{\mathrm{s}}$. (a) Initial portion of current transient and definition of $t_{\mathrm{i}}$. (b) Current transients recorded at different $E_{\mathrm{s}}$. (1) $E_{\mathrm{s}}=0.51$; (2) $E_{\mathrm{s}}=0.52 ;$ (3) $E_{\mathrm{s}}=0.53$; (4) $E_{\mathrm{g}}=0.54 ;$ (5) $E_{\mathrm{s}}=0.55 \mathrm{~V}$. 


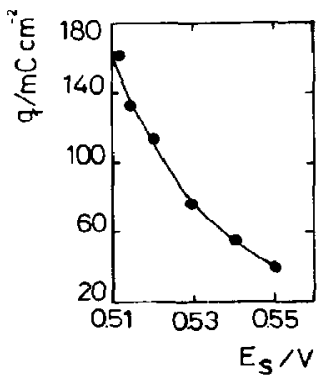

Fig. 5. Charge density resulting from current transient integration us $E_{s}$. Data from Fig. $4 b$.



Fig. 6. $j v s t^{3}$ plots for the middle rising portions of the current transients depicted in Fig. 4 b. (a) (1) $E_{\mathbf{s}}=0.52 ;$ (2) $E_{\mathrm{s}}=0.51 \mathrm{~V}$. (b) (3) $E_{\mathrm{s}}=0.55$; (4) $E_{\mathrm{s}}=0.54 \mathrm{~V}$. Time scale origin is $t=t_{i}=0$.

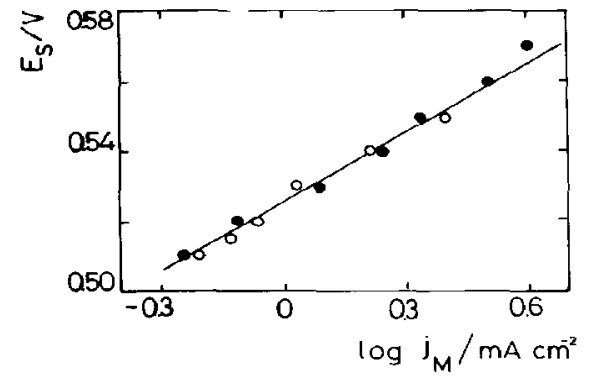

Fig. 7. Potential dependence of the current maxima resulting from the current transients. Polycrystalline Ag electrode in $0.1 \mathrm{M} \mathrm{NaOH}$. Electrode treatment as described in Fig. 4b.

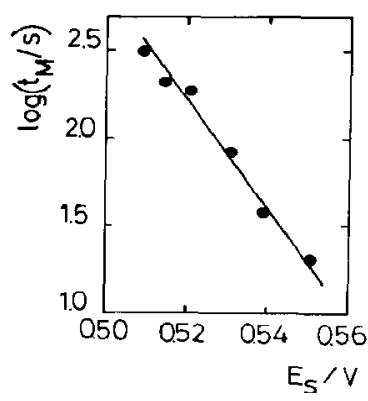

Fig. 8. Potential dependence of $t_{M}$.

nucleation stage in the $\mathrm{Ag}(\mathrm{I})$ oxide $\rightarrow \mathrm{Ag}(\mathrm{II})$ oxide reaction. This reaction involves a phase change for which both a charge transfer and a diffusion controlled growth mechanism have been proposed, based on the analysis of the current transient data. In principle, one can admit that the strong dependence of $I_{M}$ and $t_{M}$ on $E_{\mathrm{s}}$ favours a charge transfer controlled process, although simple 3-D growth models for this type of control predict that the current increases asymptotically to a limiting value when $t \rightarrow \infty$ instead of the maximum value resulting in the transients. On the other hand, it is clear from the voltammetric data that the behaviour of peak $A_{2}$ perhaps indicates the pres-

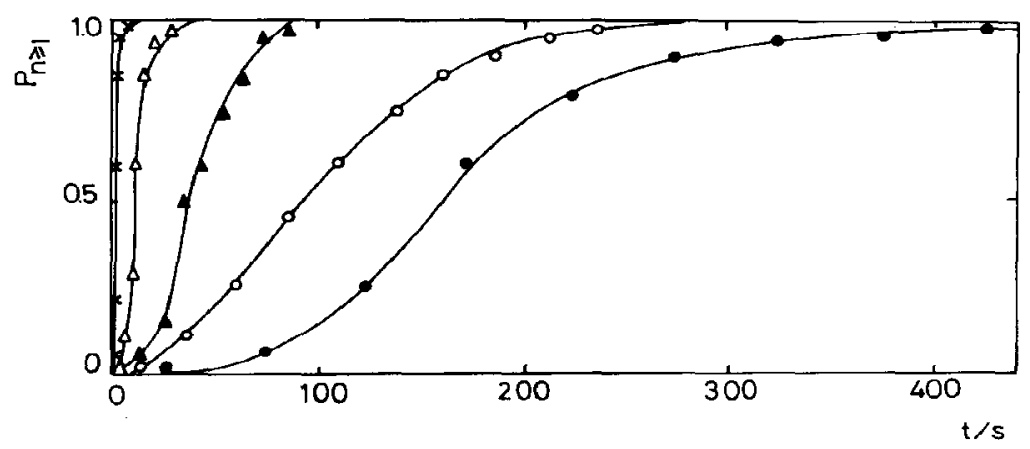

Fig. 9. Time dependence of $P_{n \succeq 1}$ for various potential steps: $(\odot) E_{\mathrm{s}}=0.51 ;(\bigcirc) E_{\mathrm{s}}=0.52 ;(\Delta) E_{\mathrm{s}}=0.53 ;(\Delta) E_{\mathrm{s}}$ $=0.54 ;(x) E_{\mathrm{s}}=0.56 \mathrm{~V}$. 
ence of mass transport limitations (Fig. 2). Otherwise, it should be noticed that 3-D growth under diffusion control requires either $I$ vs $t^{1 / 2}$ or $I$ vs $t^{3 / 2}$ linear relationships for the initial rising part of the current transients and linear $I$ vs $t^{-1 / 2}$ relationship for $t \rightarrow \infty$. However, the initial rising part of the transients actually fit linear $I$ vs $t^{3}$ instead of $I$ vs $t^{3 / 2}$ linear relationships (Fig. 6) and the portion of the transients after the maximum decays faster than that expected for a $I$ vs $t^{-1 / 2}$ plot. Nevertheless, despite these drawbacks for the present system, the progressive nucleation and 3-D growth under charge transfer control where diffusion of species from the electrode to the growing sites is essential for further expansion seems to be applicable $[23,24]$. For such a model the current-time transients for the case where pyramids are right circular cones is given by the following equations [23]:

$$
\begin{aligned}
j(t)= & z \mathrm{~F} k_{2}\left[1.0-\exp \left(-\frac{\pi M^{2} k_{1}^{2} \alpha N_{0} t^{3}}{3 \rho^{2}}\right)\right] \\
& \exp \left(\begin{array}{c}
\pi M^{2} k_{1}^{2} \alpha N_{0} t^{3} \\
3 \rho^{2}
\end{array}\right) \\
= & P_{1}\left[1.0-\exp \left(-P_{2} t^{3}\right)\right]\left[\exp \left(-P_{2} t^{3}\right)\right],
\end{aligned}
$$

where $j(t)$ is the instantaneous current density, $P_{1}=z \mathrm{~F} k_{2}, P_{2}=\pi M^{2} k_{1}^{2} \alpha N_{0} / 3 \rho^{2}, M$ is the molecular weight and $\rho$ is the density of the electroformed deposit, $N_{0}$ is the number of sites available for nucleation, $\alpha$ is the nucleation rate constant, so that $\alpha N_{0}$ is the nucleation rate, and $k_{2}$ and $k_{1}$ are the specific rate constants for crystal growth perpendicular and parallel to the electrode surface, respectively. The final factor in Equations (2) and (3) accounts for the reduction of growth caused by the diffusion of species to the growth sites. It can be noticed that the decrease in $q$ as $E_{\mathrm{s}}$ increases (Fig. 5) indicates that certain "passivation" of the electrode probably occurs through the formation of a more compact $\mathrm{Ag}$ (II) oxide layer at positive potentials which prevents the access of the reactants to the $\mathrm{Ag}(\mathrm{I})$ oxide layer. From the $q$ vs $E_{\mathrm{s}}$ dependence (Fig. 5), the change in the average thickness of the $\mathrm{AgO}$ layer with $E_{\mathrm{s}}$ can be estimated from:

$$
h=\left(\frac{M}{z \mathrm{~F} \rho}\right) q .
$$

By taking $\quad M_{\mathrm{Ag}_{2} \mathrm{O}_{2}}=246 \mathrm{~g} \mathrm{~mol}^{-1}, \quad z=2, \quad \rho=$ $7.143 \mathrm{~g} \mathrm{~cm}^{-3} ; h$ becomes 2 and $0.4 \mu \mathrm{m}$ for $E_{\mathrm{s}}=0.51$ and $0.55 \mathrm{~V}$, respectively.

Equation (3) predicts a linear $I$ vs $t^{3}$ plot for $t \rightarrow 0$, and linear $\log I_{M}$ vs $E_{\mathrm{s}}$ and $\log t_{\mathrm{M}}$ vs $E_{\mathrm{s}}$ relationships which have been proved experimentally (Figs 7 and 8 ). Furthermore, a reduced variable test for different $E_{\mathrm{s}}$ after $t_{\mathrm{i}}$ and background current subtraction, shows an excellent agreement with the theoretical curve (Fig. 10). Unfortunately, information about the nucleation stage can not be obtained from the transients as $\boldsymbol{P}_{2}$ contains the composite $k_{1}^{2} \alpha N_{0}$ term, but it can be derived through the statistical analysis of $t_{\mathrm{i}}$ and by using the $\left[1-P_{n \geqq 1}\right] v s t$ and $\ln \lambda$ vs $\eta$ plots, where $\lambda$ corresponds to an average nucleation rate derived from the plots shown in Figs 11 and 12. Therefore, on the basis of an irreversible electrochemical nucleation kinetic formalism[25], the value of the rate $\alpha N_{0}$ as derived from $\lambda / a$ ratio, $a$ being the electrode area, allows now the calculation of the rate constant $k_{1}$ from the value of $P_{2}$, and the rate constant $k_{2}$ directly from $P_{1}$. Both rate constants fit $\log k_{1}$ and $\log k_{2}$ vs $\eta$ plots with slopes close to $0.06 \mathrm{~V}$ decade (Fig. 13) but at a fixed potential the value of $k_{1}$ is practically three orders of magnitude greater than that of $k_{2}$. This difference would explain the fact that under certain conditions the overall process would approach a $2-D$ growth model. Furthermore, it should be noticed that for a progressive nucleation and 2-D growth under charge transfer control $j(t)$ is given by [26]:

$$
\begin{aligned}
j(t) & =\frac{z \mathrm{~F} \pi M h k^{2} N_{0} \alpha}{\rho} t^{2} \exp \left[-\frac{\pi M^{2} k^{2} N_{0} \alpha}{3 \rho^{2}} t^{3}\right] \\
& =P_{3} t^{2} \exp \left(-P_{4} t^{3}\right)
\end{aligned}
$$



Fig. 10. Dimensionless $\left[I / I_{\mathrm{M}}\right.$ vs $\left.t / t_{\mathrm{M}}\right]$ plots for current transients depicted in Fig. $4 \mathrm{~b}$. (A) $E_{\mathrm{s}}=0.51 \mathrm{~V} ;\left(\boldsymbol{O}_{\mathrm{s}} E_{\mathrm{s}}\right.$ $=0.52 \mathrm{~V} ;(0) E_{\mathrm{s}}=0.53 \mathrm{~V} ;(\times) E_{\mathrm{s}}=0.54 \mathrm{~V} ;(\Delta) E_{\mathrm{s}}=0.55 \mathrm{~V}$. Theoretical results from the models correspond to the three lines as follows. Progressive $(-)$ and the instantaneous $\left(-\cdot-^{-}\right)$nucleation and 3-D growth under charge transfer control for right circular cones leading to passivation. Progressive (-- - ) nucleation and 2$\mathrm{D}$ growth under charge transfer control for right cylinders growing radially. 


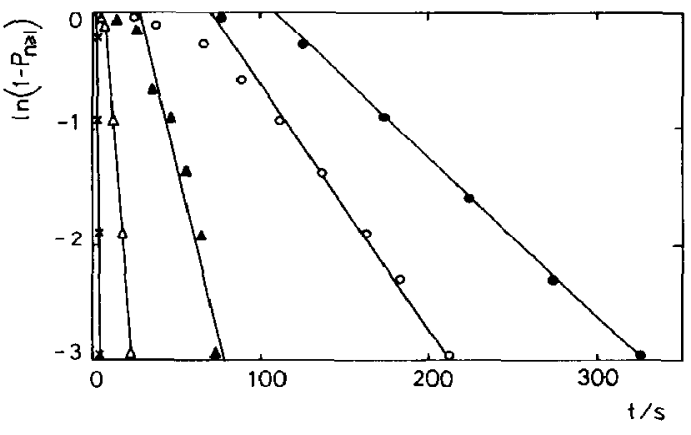

Fig. 11. In $\left(1-P_{n \geq 1}\right)$ vs $t$ plots resulting for different values of $E_{\mathrm{s}}:(\odot) E_{\mathrm{s}}=0.51 ;(O) E_{\mathrm{s}}=0.52 ;(\Delta) E_{\mathrm{s}}=0.53 ;(\Delta) E_{\mathrm{s}}=0.54$; (x) $E_{\mathrm{s}}=0.56 \mathrm{~V}$.

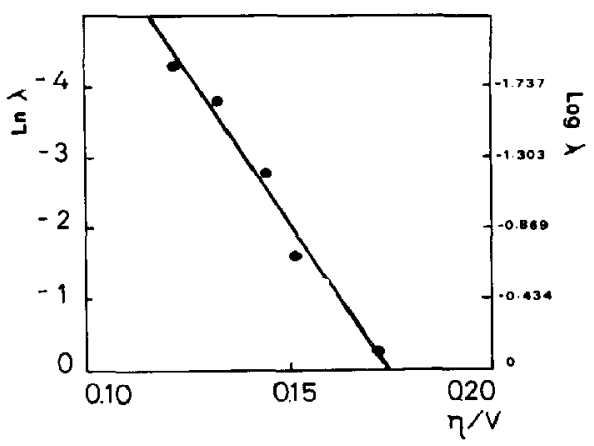

Fig. 12. Overpotential dependence of the averagc steady state nucleation rate according to the atomistic model.

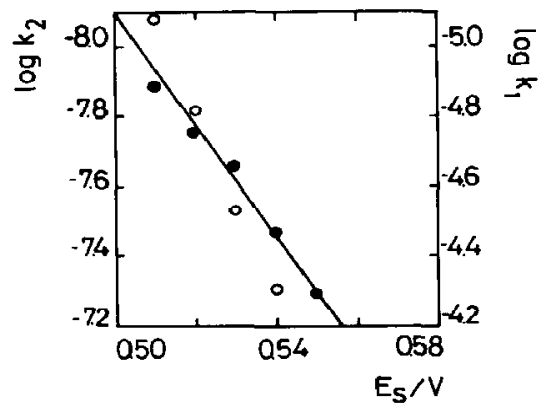

Fig. 13. Potential dependence of $k_{1}$ and $k_{2}$.

The reduced variable test for Equation (6) (Fig. 10) suggests that this model accounts for the transients behaviour for $t \rightarrow \infty$. Otherwise for $t \rightarrow 0$, the expected linear $I$ vs $t^{2}$ plots are not satisfactorily fulfilled in the short time range (Fig. 6). Therefore, from the entire kinctic analysis one can conclude that the progressive nucleation and 3-D growth model under charge transfer control followed by passivation becomes the most adequate to describe the present experimental results.

On the other hand, the following reaction sequence can account for the kinetics of the $\mathrm{Ag}_{2} \mathrm{O} \rightarrow \mathrm{AgO}$ phase change:

$$
\begin{gathered}
\left(\mathrm{Ag}_{2} \mathrm{O}\right) \mathrm{Ag}_{2} \mathrm{O}+\mathrm{OH}^{-}=\left(\mathrm{Ag}_{2} \mathrm{O}\right) \mathrm{Ag}_{2} \mathrm{O}(\mathrm{OH})_{\mathrm{ad}}+\mathrm{e}^{-}, \\
\left(\mathrm{Ag}_{2} \mathrm{O}\right) \mathrm{Ag}_{2} \mathrm{O}(\mathrm{OH})_{\mathrm{ad}}=\mathrm{Ag}_{2} \mathrm{O}+2 \mathrm{AgO}+\mathrm{H}^{+}+\mathrm{e}^{-}, \\
\mathrm{AgO}+\mathrm{N}=\mathrm{AgO}(\mathrm{N}), \\
\mathrm{AgO}+\mathrm{AgO}(\mathrm{N})=(\mathrm{AgO})_{2}(\mathrm{~N})^{*}, \\
\mathrm{AgO}+(\mathrm{AgO})_{2}(\mathrm{~N})=(\mathrm{AgO})_{3}(\mathrm{~N}), \\
\mathrm{AgO}+(\mathrm{AgO})_{n-1}(\mathrm{~N})=(\mathrm{AgO})_{n}(\mathrm{~N}),
\end{gathered}
$$

where $\mathbf{N}$ denotes a preferred site in the $\mathrm{Ag}(\mathrm{I})$ oxide layer where nucleation of the $\mathrm{AgO}$ species takes place, the asterisk denotes the critical nucleus. Equations (7) and (8) imply successive electron transfer steps and Equation $(9 a)-9 d)$ represent the nucleation and growth stage.

The physical picture of the postulated model means that when the applied potential exceeds the potential of the $\mathrm{Ag}_{2} \mathrm{O} / \mathrm{AgO}$ redox couple $\left[E_{\mathrm{r}}\left(10^{-1} \mathrm{M} \mathrm{NaOH}\right) / v s\right.$ $s c e=0.388]$ the outer part of the $\mathrm{Ag}_{2} \mathrm{O}$ layer is electrooxidized yielding a critical supersaturation of AgO species. So that nuclei of AgO, probably dimers, are progressively formed and grow under charge transfer control, the mode of growth of nuclei approaching circular right cones.

On the other hand, at low $\eta$ values, that is for low supersaturations, isolated centres of $\mathbf{A g}(\mathrm{II})$ oxides grow slowly, and under this condition the $\mathrm{OH}^{-}$ions can react easily with the remaining Ag(I) oxide crystals. Oppositely at high $\eta$ values, ie large supersaturations, a large number of centres grow rapidly yielding a compact $\mathbf{A g}(\mathrm{II})$ oxide layer which prevents further reaction between the $\mathrm{OH}^{-}$ions and the $\mathrm{Ag}(\mathrm{I})$ oxide crystals. This explains the "passivation" of the $\mathbf{A g}(\mathbf{I})$ oxide electrode as $\eta$ increases. It should also be noticed that in agreement with the advanced interpretation of the present results Monte Carlo simulations of crystal growth at low supersaturations indicate elongated shapes instead of the more compact cap-shaped crystallites formed at high supersaturations $[27,28]$.

Acknowledgement-This work was financially supported by the Consejo Nacional de Investigaciones Cientificas y Técnicas and the Comisión de Investigaciones Científicas de la Provincia de Buenos Aires. This work was also partially supported by the Regional Program for the Scientific and Technological Development of the Organization of the American States.

JGB thanks the Deutscher Akademischer Austauschdienst (DAAD) for the fellowship granted through the Partnership Agreement between the University of La Plata (Argentina) and the University of Mainz (West Germany).

\section{REFERENCES}

1. L. Young, Anodic Oxide Films, p. 302, Academic Press, London (1961).

2. J. P. Hoare, The Electrochemistry of Oxygen, p. 211, Interscience, New York (1968).

3. B. V. Tilak, R. S. Perkins, H. A. Kozlowska and B. E. Conway, Electrochim. Acta 17, 1447 (1972).

4. N. A. Shumilova and G. V. Zhutaeva, in Encyclopedia of Electrochemistry of the Elements (Edited by A. J. Bard), Vol. VIII, p. 1, Dekker, New York (1978). 
5. J. M. M. Drogg and F. Huisman, J. electroanal. Chem. 115, 211 (1980).

6. B. G. Pound, D. D. McDonald and J. W. Tomlinson, Electrochim. Acta 25, 563 (1980).

7. B. G. Pound, D. D. MacDonald and J. W. Tomlinson, Electrochim. Acta 25, 1293 (1980).

8. P. Stonehart, Electrochim. Acta 13, 1789 (1968).

9. G. T. Burnstein and R. C. Newman, Electrochim. Acta 25 , 1009 (1980)

10. M. López Teijelo, J. R. Vilche and A. J. Arvia, J. electroanal. Chem. 131, 331 (1982).

11. I. Dugdale, M. Fleischmann and W. F. K. Wynne-Jones, Electrochim. Acta 5, 229 (1961).

12. M. Fleischmann, D. J. Lax and H. R. Thirsk, Trans. Faraday Soc. 64, 3128 (1968).

13. I. M. M. Drogg, P. T. Arderliesten and G. A. Bootsma, J. electroanal. Chem. 99, 173 (1979).

14. G. W. D. Briggs, M. Fleischmann, D. J. Lax and H. R. Thirsk, Trans. Faraday Soc. 64, 3120 (1968).

15. J. Gomez Becerra, R. C. Salvarezza and A. J. Arvia, Electrochim. Acta 33, 1431 (1988).

16. R. G. Barradas and G. H. Fraser, Can. J. Chem. 42, 2488 (1964).
17. P. Stonehart and F. P. Portante, Electrochim. Acta 13, 1805 (1968).

18. M. Fleischmann, D. J. Lax and H. R. Thirsk, Trans. Faraday Soc. 64, 3137 (1968).

19. R. S. Perkins, B. V. Tilak, B. E. Conway and H. A. Kozlowska, Electrochim. Acta 17, 1471 (1972).

20. M. López Teijelo, J. R. Vilche and A. J. Arvia, J. appl. Electrochem. in press.

21. C. P. Wales and J. Burbank, J. electrochem. Soc. 106, 855 (1959).

22. A. Milchev and V. Tsakova, Electrochim. Acta 30, 133 (1985).

23. R. D. Armstrong, M. Fleischmann and H. R. Thirsk, J. electroanal. Chem. 11, 208 (1966).

24. R. G. Barradas, P. C. Benson, S. Fletcher and J. D. Porter, J. electroanal. Chem. 85, 57 (1977).

25. S. Fletcher, J. electroanal. Chem. 215,1 (1986).

26. M. Fleischmann and $\mathbf{H}$. R. Thirsk, Advances in Electrochemistry and Electrochemical Engineering (Edited by P. Delahay), Vol. 3, p. 123, Wiley New York (1963).

27. D. Kashchiev, J. Crystal Growth 40, 29, 47 (1977).

28. D. Kashchiev, J. Crystal Growth 67, 559 (1984). 